\title{
Meyve ve Sebzelerde Aktif Ambalajlama Teknolojisinin Kullanımı
}

\author{
Mehmet Seçkin Aday ${ }^{1 *}$ \\ 1* Çanakkale Onsekiz Mart Üniversitesi, Mühendislik Fakültesi, Gıda Mühendisliği Bölümü, Çanakkale, Türkiye (ORCID: 0000-0002-5669-5812), \\ mseckinaday@comu.edu.tr
}

(İlk Geliş Tarihi 14 Ekim 2020 ve Kabul Tarihi 10 Ocak 2021)

(DOI: $10.31590 /$ ejosat.840317)

ATIF/REFERENCE: Aday, M. S. (2021). Meyve ve Sebzelerde Aktif Ambalajlama Teknolojisinin Kullanımı. Avrupa Bilim ve Teknoloji Dergisi, (21), 122-130.

\section{$\ddot{O} z$}

Son yıllarda tüketicilerin daha sağlıklı bir yaşam tarzına ve besleyici değeri yüksek olan gıdalara yönelmeleri nedeniyle taze meyve ve sebzelere olan talep artmaktadır. Fakat taze meyve ve sebzeler hasat sonrasında da canlilıklarını devam ettirmekte olup, solunum ve terleme gibi birçok reaksiyonun hızı ortam koşullarına ve uygulanan hasat sonrası muhafaza metotlarına göre değişmektedir. Taze meyve ve sebzelerde kullanılan hasat sonrası muhafaza metotlarının en önemli amacı; solunum hızını yavaşlatmak ve mikrobiyal bozulmayı geciktirmektir. Fakat hangi metot kullanılarsa kullanılsın, kullanılan ambalajlama teknolojisi ve ambalaj materyalleri taze meyve ve sebzelerde raf ömrünü doğrudan etkilemektedir. Geleneksel ambalajlama teknolojileri; içerme, koruma, iletişim ve kullanım kolaylığı sağlama fonksiyonlarına sahip olup, genel amaç ambalaj ürün etkilişiminin inert olmasıdır. Bununla birlikte tüketicilerin yaşam tarzlarının değişmesi, daha taze ve katkı maddesi kullanılmayan ürünleri tercih etmesi ve perakende uygulamalarındaki değişiklikler, yeni ambalaj teknolojilerindeki gelişmeleri tetiklemektedir. Bu teknolojilerden bir tanesi olan aktif ambalajlama, ambalajlara eklenen çeşitli bileşenlerle (oksijen, karbondioksit, etilen tutucular, nem düzenleyiciler veya antimikrobiyaller) meyve ve sebzelerin kalitelerinin korunması ve raf ömrünün uzatılması konusunda gıda endüstrisine alternatif çözümler sunmaktadır. Oksijen tutucular ambalaj içerisindeki oksijen konsantrasyonu azaltarak solunum hızının düşürülmesini sağlarken, karbondioksit tutucular fazla karbon dioksitin üründe meydana getireceği olumsuz değişiklikleri engellemek için kullanılmaktadır. Etilen tutucular klimaterik meyvelerde yaşlanma reaksiyonlarını azaltmak için ambalajlara eklenmektedir. Nem düzenleyiciler ise ambalaj içerisindeki yüksek nem dolayısıyla meyve ve sebzelerde gerçekleşen istenmeyen değişimleri engellemek amacıyla kullanılmaktadır. Antimikrobiyal bileşenler de mikrobiyal bozulmayı azaltmak ve gıda güvenliğini sağlamak için meyve ve sebzeler ambalajlarında yer almaktadır. Bu derleme makalede, aktif ambalajlamada kullanılan bileşenler özetlenmiş ve bu bileşenlerin meyve ve sebzelerdeki uygulamaları açıklanmıştır.

Anahtar Kelimeler: Meyve, Sebze, Aktif ambalajlama, Raf ömrü.

\section{The Use of Active Packaging Technology in Fruits and Vegetables}

\begin{abstract}
Demand for fresh fruits and vegetables has been increasing in recent years as consumers tend to a healthier lifestyle and foods with high nutritional value. However, fruits and vegetables continue to live after they have been harvested and the rate of many reactions such as respiration and transpiration varies according to the environmental conditions and post-harvest methods applied. The most important goals of post-harvest preservation methods used in fresh fruits and vegetables includes reducing the respiration rate and delaying the microbial spoilage. Whichever method is used, the packaging technology and packaging materials directly affect the shelf life of fresh fruits and vegetables. Traditional packaging technologies include the functions of containment, preservation, communication, and ease of use but the general aim to make these traditional packages is to maintain inert conditions between package and food. In addition, changes in consumers' lifestyles, preference for fresh and additive-free products and retail practices promotes the developments in new packaging technologies. Active packaging, one of these technologies, offers alternative solutions to the food industry by preserving the quality of fruits and vegetables and extending their shelf life with various components (oxygen, carbon dioxide, ethylene scavengers, moisture regulators or antimicrobials) added to the package. Oxygen scavengers slow down the respiration rate by reducing the oxygen concentration in the package and carbon dioxide scavengers are used to prevent the negative changes in the product caused by excess carbon dioxide concentration. Ethylene scavengers are added to packages of climatic fruits to reduce senescence reactions. Moisture regulators are used to avoid unwanted changes in fruits and vegetables due to high humidity in the package. Antimicrobial compounds
\end{abstract}

*Sorumlu Yazar: mseckinaday@comu.edu.tr 
are also used in fruits and vegetables to reduce microbial spoilage and ensure food safety. In this review article, the components used in active packaging are summarized and applications of these ingredients in fruits and vegetables packages are explained.

Keywords: Fruit, Vegetable, Active packaging, Shelf-life.

\section{Giriş}

Ambalajlama günümüzün gelişmiş toplumlarında çok önemli bir yer tutmaktadır. Özellikle taze meyve ve sebzeler dahil olmak üzere, gıda maddelerinin çoğu ambalajlar içerisinde pazarlandığından, bu sektörde olağanüstü gelişmeler yaşanmaktadır (Lopez-Rubio ve ark., 2004).

Gıda üretim süreçlerinden bir tanesi olan ambalajlama; depolama ve taşıma sırasında gıda ürünlerinin kalitesini çevresel etkenlere karşı korumada önemli bir fonksiyona sahiptir. Çoğu gıdanın kalitesinin nem emilimi, oksijene maruz kalma, istenmeyen koku emilimi ve ambalaj bileşenlerinin gıdaya taşınması gibi kütle aktarım proseslerinden etkilendiği bilinmektedir. Tüm bu olaylar; gıda ile onu çevreleyen atmosfer arasında veya gida ile ambalaj malzemesi arasında gerçekleştiğinden, kullanılan ambalajlama teknolojisinin gıdanın raf ömrünü doğrudan etkilediği söylenebilmektedir (Galić ve ark., 2011). Gida ambalajları ayrıca bu koruma fonksiyonuyla birlikte, gıdalar hakkında gerekli bilgileri iletme ve tüketiciye kullanım kolaylığı sağlamayı da amaçlamaktadır (Han, 2014).

Geleneksel gıda ambalajları yukarıda tanımlanan tüm fonksiyonları içermesine rağmen, bu ambalaj malzemelerindeki temel prensip; gıda ile ambalaj arasındaki etkileşimi minimuma indirgemek yani mümkün olduğunda inert olmaktır (Rooney, 1995). Geleneksel ambalaj teknolojilerine alternatif olarak geliştirilen yeni teknolojiler ise perakende uygulamalarındaki değişiklikler (pazarın küreselleşmesi sonucu dağıtım süresinin uzaması) veya tüketicilerin yaşam tarzındaki farklılaşmalar (hızlı bir yaşam döngüsü sonucu, pazarda alışverişe veya yemek pişirmeye daha az zaman ayırma) nedeniyle ambalajların daha aktif bir oynamasını sağlamıştır (Lopez-Rubio ve ark., 2004). Bu kapsamda geliştirilen yenilikçi ambalajlama teknolojilerine örnek olarak; biyobozunur polimerler; mikroperfore filmler, akıllı ve aktif ambalaj materyalleri verilebilmektedir. Fakat aktif ve akıllı ambalajlama terimi çeşitli literatürlerde eş anlamlı olarak kullanıldığından, iki terim arasındaki farklılığın netleştirilmesi gerekmektedir. $\mathrm{Bu}$ kapsamda akıllı ambalajlama; ambalaj üzerinde yer alan çeşitli indikatörler vasıtasıyla gıdada meydana gelen değişimlerin izlenmesine olanak sağlayan teknolojidir. Aktif ambalajlama ise; gida ve ambalaj arasında istenen etkileşimlerin meydana gelmesine yardımcı olmak ve raf ömrünü uzatmak amacıyla ambalaja eklenen aktif bileşenlerden meydana gelmektedir (Aday ve Yener, 2014).

Aktif ambalajlamanın kullanıldığı ürün gruplarından bir tanesi olan taze meyve ve sebzeler; yaşlanmayı geciktirmesi, kanser ve akciğer gibi çeşitli hastalıklara yakalanma riskini azaltması gibi sağlık açısından birçok yararlar sunmaktadır (Çağlar ve Demirci, 2018). Özellikle son yıllarda tüketiciler sayılan sağlıkla ilgili endişelerden dolayı diyetlerinde bu tür gıdaların yer almasına çok önem vermektedir (Demirgül ve Sağdıç, 2018; Garipoğlu, 2019). Fakat meyve ve sebzeler hasat sonrası canlılıklarını devam ettirdiklerinden ve son derece çabuk bozulabilir olmalarından dolayı diğer birçok gıda ürününe kıyasla zorluklar içermektedir. Çünkü ambalaj materyalinin geçirgenlik özellikleriyle, içerdiği ürünün oksijen, karbondioksit veya etilen ihtiyacının eşleştirilmesi zor olduğundan, çeşitli ödünler verilmektedir. Bu ödünleri vermemek için ambalajların pasif bir konumda olmaması ve ürünün fizyolojik durumuna yanıt verecek aktif bir konumda olması gerekmektedir (Scully ve Horsham, 2007).

$\mathrm{Bu}$ kapsamda aktif ambalajlama özellikle meyve ve sebzelerde kalitenin korunması ve gıda güvenliğinin artırılması amacıyla çeşitli alt dallardan oluşmakta olup, bunlara örnek olarak oksijen tutucular, karbon dioksit tutucu/salıcılar, nem düzenleyiciler, etilen tutucular ve antimikrobiyal ambalajlar verilebilir (Rooney, 1995). Aktif ambalajlama; aktif özellikteki maddenin, kullanılan ambalaj materyalinin polimer matriksinin içerisine veya yüzeyine yedirilmesiyle sağlanabileceği gibi aynı zamanda saket şeklinde veya şişe kapaklarına eklenmesiyle de sağlanabilmektedir (Dainelli ve ark., 2008).

Aktif ambalajlama konsepti üzerine literatürde birçok çalışma bulunsa da, bu çalışmalar genellikle aktif bileşenlerin ambalaj filmleri üzerindeki etkilerinin incelenmesine yöneliktir. $\mathrm{Bu}$ nedenle derleme, aktif ambalajlama teknolojisinin meyve ve sebze sektöründeki potansiyeline odaklanmaktadır. Ayrıca aktif ambalajlama teknolojisine tüketici bakış açısını da değerlendirilmekte olup, konu üzerine olan yasal düzenlemeler hakkında da bilgi vermektedir.

\section{Aktif Ambalajlama Bileșenleri}

\subsection{Oksijen Tutucular}

Birçok durumda gıdanın bozulmasına, oksijen sebebiyle gıda bileşenlerinin oksidasyonu veya küfler neden olmaktadır. Gıdalarda gerçekleşen oksidatif reaksiyonlar sonucu; kötü kokular, istenmeyen tatlar, renk değişiklikleri ve besin değerinde düşme gibi olumsuz durumlar meydana gelmektedir. Meyve ve sebzeler özelinde; solunumun hızlanması, askorbik asit kaybı, bozulmaya neden olan mikroorganizmaların gelişmesi, enzimatik ve enzimatik olmayan reaksiyonların gerçekleşmesi bu reaksiyonlara örnek olarak verilebilmektedir (Brody ve ark., 1995). Bu olumsuzluklar nedeniyle oksijene duyarlı gidalar; modifiye atmosfer paketleme (MAP) veya vakumlu paketleme kullanılarak ambalajlansa da, bu teknolojiler her zaman $\mathrm{O}_{2}{ }^{\prime} \mathrm{yi}$ tamamen ortamdan uzaklaştıramamaktadır. Ayrıca, çevreden ambalaj filmleri vasıtasıyla ambalaj içerisine giren $\mathrm{O}_{2}$ bu tekniklerle elimine edilememektedir (Vermeiren ve ark., 1999). Aktif ambalajlamada kullanılan oksijen tutucular ise gidada çözünmüş olan veya dışarıdan ambalaj içerisine giren oksijeni gidererek oksidatif reaksiyonları geciktirmektedir. Bu kapsamda kullanılan oksijen tutucular; tepe boşluğunda saket şeklinde veya ambalaj malzemesine/kapaklara doğrudan dahil edilme şeklinde kullanılabilmektedir. Oksijen tutucular; oksijenle reaksiyona girerek, ambalaj içi oksijen konsantrasyonunu azaltan bileşikler olarak tanımlanmaktadır (Brody ve ark., 2008). Bu amaçla kullanılan oksijen tutucular genellikle demir ve demir oksitin oksidasyonuna bağlı olarak işlev görmektedir. $\mathrm{Bu}$ bileşenler ambalajlanmış gıda tarafından çeşitli fizyolojik reaksiyonlar sonucu üretilen su ile reaksiyona girerler ve hidrate olmuş metalik ajanları meydana getirerek oksijeni tutarlar ve kararlı bir oksite çevirirler. Fakat bu şekilde meydana gelebilecek metalik tatların gıdalara geçmesini önlemek için; askorbik asit, sülfitler, kateşol, askorbat tuzları, etanol oksidaz veya glukoz oksidaz gibi bileşenlerden de yararlanılmaktadır (Han ve ark., 2018). Saket formu dışında, oksijen tutucular yüksek yoğunluklu polietilen ile 
karıştırılmakta ve böylelikle su buharının dışardan içeriye girmesi kolaylaştırılarak oksijen ile aktif bileşenlerin reaksiyonu sağlanmaktadır. Fakat bu şekilde üretilen plastik filmlerin ve laminatların oksijen tutma kapasitesi, saketlerle karşılaştırıldığında daha düşüktür (Ahmed ve ark., 2017). Bazı özel uygulamalarda ise oksijen tutucuların istenilenden önce reaksiyona girmesini engellemek için içerisine 1şığa duyarlı boyalar eklenmekte ve sonrasında ultraviyole 1 şı altında aktive edilmektedir (Lopez-Rubio ve ark., 2004). Ticari uygulamalardaki mevcut eğilim ise, kazara yırtılmayı takiben saketteki aktif maddenin yutulmasını önlemek için, $\mathrm{O}_{2}$ tutucuları ambalaj malzemesine dahil etmek şeklindedir (Suppakul ve ark., 2003).

Oksijen tutucularla ilgili taze meyve ve sebzeler üzerine yapılan çalışmalar incelendiğinde, çilek ambalajlarına yerleştirilen oksijen tutucular mikroperfore filmlerle kullanılmış ve sonuç olarak ambalaj içi optimum gaz konsantrasyonuna erişildiği ve buna bağlı olarak çilek kalitesinin oksijen tutucu kullanılmayanlara göre daha iyi olduğu tespit edilmiştir (Kartal ve ark., 2012). Diğer bir çalışmada ise oksijen tutucular domates ambalajlarına yerleştirilmiş ve sonuçlara göre oksijen tutucuların ambalaj içi gaz kompozisyonunun dengeye ulaşma süresini kısalttığı ve modifiye atmosfer ambalajlama uygulamalarında başarıyla kullanılabileceği belirtilmiştir (Charles ve ark., 2003). Hindiba üzerine yapılan ve aktif ve pasif ambalajlamanın ürün kalitesi üzerindeki etkisinin değerlendirildiği çalışmada, oksijen tutucu kullanılan aktif ambalajlama uygulamasının pasif ambalaja göre esmerleşme reaksiyonlarını yavaşlattı̆̆ tespit edilmiştir (Charles ve ark., 2008). Aktif ambalajlamanın hindiba üzerindeki mikrobiyal etkinliğinin değerlendirildiği diğer bir çalışmada da oksijen tutucuların Pseudomonas ve Enterobacteria popülasyonunun gelişimini inhibe ettiği sonucuna varılmıştır (Charles ve ark., 2005). Aday ve Caner (2013) tarafindan gerçekleştirilen araştırmada da çilek ambalajlarında oksijen tutucu kullanılmasının, sertlik ve renk değerlerinin korunmasında faydalı olduğu, ayrıca küflenmeyi azalttığı ve duyusal skorlar bakımından da daha iyi sonuçlar aldığı tespit edilmiştir.

Oksijen tutucuların saket veya film olarak kullanılması konusunda bazı zorluklar da bulunmaktadır. Aktif bileşenlerin filmlere eklenmesinden sonra, kesme kuvveti ve yüksek basınç gibi film üretimi sirasında meydana gelen etmenler, oksijen tutucuların kapasitelerini yitirmelerine neden olmaktadır. Ayrıca, film işleme sırasında aktif bileşen olarak kullanılan organik bazlı bileşenler ekstrüzyon gibi yüksek sıcaklıklarda stabil kalamamaktadır. Diğer bir sorun ise oksijen tutucu sistemlerin polimer matriks içine dahil edilmesinin filmlerin gaz bariyeri, termal ve optik özelliklerini etkilemesidir (Gaikwad ve ark., 2018). Bu nedenlerden dolayı oksijen tutucuların uygulanmasında birçok faktörün dikkate alınması gerekmektedir.

\subsection{Karbondioksit Tutucular/Salıcılar}

Ambalaj içerisindeki yüksek karbondioksit seviyeleri genellikle mikrobiyal büyümeyi geciktirmede yararlı bir rol oynamaktadır (Ozdemir ve Floros, 2004). $\mathrm{CO}_{2}$ 'nin antimikrobiyal etkisi, gıdalardaki yüksek çözünürlügü ile ilgilidir ve $\mathrm{CO}_{2}$ gazı, düşük sıcaklıklarda su ve yağ içeriği yüksek gıdalarda daha fazla çözündüğünden, soğutulmuş koşullar altında saklanan gıdalardaki etkisi daha belirgindir (Lee, 2016). Fakat fazla $\mathrm{CO}_{2}$ miktarı da ürünleri olumsuz yönde etkilemekte ve ürünlerde tolerans limitlerinin üstüne çıkılması sonucunda renkte değişimler, istenmeyen aroma bileşiklerinin gelişimi veya içsel dokularda parçalanmaların meydana gelmesini sağlayabilmektedir
(Watkins, 2000). Bu nedenle meyve ve sebzenin solunumla ürettiği $\mathrm{CO}_{2}$ miktarının, ambalajdan çıkması gereken $\mathrm{CO}_{2}$ miktarıyla iyi eşleşmesinin sağlanması (Lee, 2016) ve bu şekilde $\mathrm{CO}_{2}$ miktarının ambalaj içinde optimum seviyelerde tutularak, meyve ve sebzelerin solunum hızının azaltılması ve etilen üretiminin yavaşlatılması gerekmektedir (Ozdemir ve Floros, 2004). Ambalajdan çıkması gereken $\mathrm{CO}_{2}$ ile solunumda üretilen $\mathrm{CO}_{2}$ 'nin iyi eşleştirilememesi durumunda kullanılabilecek alternatif bir yöntem de karbondioksit tutucuların kullanımıdır. Karbondioksit tutucular genellikle kalsiyum hidroksit, sodyum hidroksit, potasyum hidroksit veya silika jel içermekte olup, karbondioksitin hidroksitlerle reaksiyonu sonucu karbonatlar meydana gelmektedir (Day ve Potter, 2011). Bu bileşenler dışında aktif kömür, zeolit ve magnezyum oksit'te $\mathrm{CO}_{2}$ tutucu özelliğe sahiptir. Fakat aktif kömür ve zeolitin, neme eğiliminin $\mathrm{CO}_{2}{ }^{\prime} \mathrm{ye}$ göre daha fazla olması, bu bileşenlerin sadece düşük nem koşullarında iyi işlev görmesini sağlamaktadır (Ozdemir ve Floros, 2004). Aktif karbonun ucuz ve erişimi kolay olan meyve kabuklarından da üretilebilir olması, kullanım potansiyelini artırıcı diğer bir etmen olarak göze çarpmaktadır (Açışlı, 2019).

Gıda ambalajı için kullanılan birçok plastik filmin karbon dioksit geçirgenliği, oksijenden daha fazla olduğundan, ambalajın içindeki karbondioksitin çoğu genellikle film vasıtasıyla dışarı çıkmaktadır. $\mathrm{Bu}$ nedenle ambalaj filminin karbondioksit geçirgenliğinin yüksek olduğu durumlarda, solunum hızını azaltmak ve mikrobiyal büyümeyi bastırmak için bir karbondioksit yayan sistem de gerekli olabilmektedir (Ozdemir ve Floros, 2004). Ambalajlarda $\mathrm{CO}_{2}$ salıcıların kullanılması sonucunda; ambalaj tepe boşluğunda bulunan $\mathrm{CO}_{2}$ seviyesi korunarak, ambalaja daha fazla ürün konması sağlanabilecek ve bu şekilde kullanılacak ambalaj sayısında azalmaya gidilebilecektir. Ayrıca iyi ayarlanmış bir karbondioksit salınımı, depolamanın ilk aşamalarında gıda ürünü tarafından gerçekleştirilen $\mathrm{CO}_{2}$ emilimini telafi ettiğinden ambalaj deformasyonunu da önleyebilecektir (Yildirim ve ark., 2018). $\mathrm{CO}_{2}$ salınımı sağlayan saketlerin içerisinde genellikle demir karbonat bulunmakta olup, reaksiyonların metal karbonatların asidik ortamda çözünmesi ve daha sonra karbon dioksit salınımını sağlamasına dayandığı düşünülmektedir (Vilela ve ark., 2018). Bazı durumlarda ise, saketler hem $\mathrm{O}_{2}$ tutarken hem de eşzamanl olarak $\mathrm{CO}_{2}$ salmaktadır. $\mathrm{Bu}$ tür sistemler, demir karbonat ya da askorbik asit ve sodyum bikarbonat karışımından meydana gelmektedir. $\mathrm{Bu} \mathrm{O}_{2}$ tutucular/ $\mathrm{CO}_{2}$ salıcilar, esas olarak ambalaj hacmi ve ambalaj görünümünün önemli olduğu ürünlerde kullanılmaktadır (Vermeiren ve ark., 1999). Bu konu üzerine yapılan çalışmada, sodyum askorbat, sodyum bikarbonat, sodyum karbonat-10-hidrat ve demir sülfat-7-hidrat, oksijenin etkili bir şekilde uzaklaştırılmasını sağlamış ve karbondioksiti serbest bırakmayı başarmıștır. Çalışmada kullanılan tüm bileşenlerin GRAS statüsündeki katkı maddeleri olmasından dolayı, bu bileşenlere dayalı formülasyonların gıda ambalajı için güvenli olduğu vurgulanmıştır (Huang ve ark., 1999). Demir karbonat ve askorbik asitten oluşan aktif bileşenin ise $1: 1$ oranında $\mathrm{CO}_{2}$ üretip, $\mathrm{O}_{2}$ tükettiği saptanmıştır (Hurme ve ark., 2002).

Karbondioksit tutucuların meyve ve sebzelerdeki uygulamalarına bakıldığında, Aday ve ark. (2011) tarafından yapılan çalışmada çileklerin kalitesinin korunması amacıyla ambalaja eklenen $\mathrm{CO}_{2}$ tutucuların, denge atmosfer koşullarının oluşumuna katkı sağladığı ayrıca pH, suda çözünür kuru madde ve renk değişimlerini kontrol grubuna göre azalttığı saptanmıştır. Armutlar üzerinde $\mathrm{CO}_{2}$ tutucuların etkinliğinin değerlendirildiği diğer bir araştırmada da, ambalaj içi karbondioksit seviyelerinin 
başarıyla düşürüldüğü, renk ve tekstür bakımından da örneklerin kalitesinin korunduğu belirlenmiştir (Nugraha ve ark., 2015). Veasna ve ark. (2012) tarafindan patlicanda 1-MCP ile birlikte uygulanan $\mathrm{CO}_{2}$ tutucunun ürünün bozulmasını geciktirdiğini, ayrıca iç ve dış soğuk zararlanması indeksini de azalttığı tespit edilmiştir. Yüksek $\mathrm{CO}_{2}$ konsantrasyonlarına duyarlı olan Shiitake mantarları üzerine yapılan çalışmada, $\mathrm{CO}_{2}$ tutucu içeren bir MAP sisteminin, $\mathrm{O}_{2}$ konsantrasyonunu yaklaşık \% 9'da ve $\mathrm{CO}_{2}$ konsantrasyonunu da \% 1-4'te tutarak bozulma reaksiyonlarını yavaşlattığı rapor edilmiştir (An, 2016).

Gıdalar tarafından gerçekleştirilen $\mathrm{CO}_{2}$ üretiminin basit bir süreç olmaması, zamanla ve diğer koşullarla değişen bir süreç içermesi nedeniyle, $\mathrm{CO}_{2}$ tutucuların uygulanmasında çeşitli zorluklarla karşılaşılmaktadır. Ayrıca, gıdanın türüne, modifiye atmosfer gibi ambalaj koşullarına ve diğer emicilerin mevcudiyetine bağlı olarak ambalajlarda $\mathrm{CO}_{2}$ 'nin emilimi; su buharı ve diğer gazlara da bağlı olarak değişmektedir. Bu nedenle $\mathrm{CO}_{2}$ tutucu sistemlerin optimizasyonu; gida, ambalaj malzemesi, tutucu ve çevre arasındaki etkileşimlere doğrudan bağlantılı olduğundan $\mathrm{CO}_{2}$ 'nin çözünmesi, absorpsiyonu ve geçirgenlik parametrelerinin iyi biçimde ayarlanması gerekmektedir (Lee, 2016).

\subsection{Etilen Tutucular}

Meyvelerin olgunlaşması bir seri biyokimyasal, fizyolojik ve yapısal değişimlere bağlı olup, bu değişiklikler ürünün tüketiciye daha alınabilir görünmesini sağlamaktadır. Bu reaksiyonlar her meyvede farklı seyir izlese de esas olarak, meyvelerin klimakterik olup olmamalarına göre değişmektedir. Klimakterik ürünlerde etilen üretimi keskin bir yükselme göstermekte ve bunun sonucunda da renk, aroma, tekstür ve diğer biyokimyasal gelişmeler meydana gelmektedir. Klimakterik olmayan ürünlerde ise biyokimyasal değişimler etilenden bağımsız gerçekleşmektedir (Lelièvre ve ark., 1997). Bitkisel hormon olarak bilinen etilen; olgunlaşma dışında kaliteyi de etkilemekte ve en önemlisi solunum hızı üzerine etki ederek yumuşama ve yaşlanma reaksiyonlarının artmasına neden olmaktadır. Ayrıca etilen; marulda kahverengileşme, bezelyede sarılaşma, havuçta acı tat oluşumu veya kuşkonmazda sertleşme gibi fizyolojik bozuklukları meydana getirmektedir (Gavara ve ark., 2009). Bazı durumlarda ise etilenin pozitif etkisinden de bahsedilebilmekte olup, narenciye ürünlerde olgunlaşmada istenilen bir faktör olarak göze çarpmaktadır. Fakat, genel olarak bakıldığında ürünlerin görsel ve organoleptik kalitesinin korunması için, ambalaj içerisindeki etilen oluşumunun azaltılması gerekmektedir (Vermeiren ve ark., 1999).

Ambalajdaki etilen miktarının ayarlanması için yaklaşımlar üç ana tipe ayrılabilmektedir: birincisi, etilenin azaltılması (modifiye atmosfer paketleme yoluyla tepe boşluğundaki gazları değiştirme); ikinci olarak, mikroperfore ambalaj malzemesinin kullanılması (gazların ambalajın içine ve dışına nüfuz etmesi için mikro delikli ambalaj malzemeleri kullanma); ve üçüncü olarak, etilenin uzaklaştırılması (etilen tutucu kullanma) (Gaikwad ve ark., 2020). En iyi bilinen, ucuz ve yaygın olarak kullanılan etilen tutma sistemi, silika içine gömülmüş potasyum permanganattan oluşmaktadır. Silika etileni emmekte ve potasyum permanganat ise onu etilen glikole okside etmektedir. Silika, etilenin tutulması için oldukça geçirgen bir saket içinde tutulmakta veya bir ambalaj filmine dahil edilebilmektedir. Bununla birlikte, potasyum permanganatın, toksisitesinden dolayı ambalaj filmlerinin gida ile temas eden yüzeylerine entegre edilmemesi gerekmektedir (Zagory, 1995). Bu tutucularda permanganat içeriği \% 4 ile \% 6 arasında değişmekte olup, potasyum permanganat etileni oksitledikten sonra rengi mordan kahverengiye değişmektedir (Prasad ve Kochhar, 2014). Etileni absorbe etmek için mevcut başka bir sistem, zeolitin potasyum permanganat ile birleştirilmesi ve ardından zeolitin bir kuaterner amonyum katyonu ile kaplanmasına dayanmaktadır. $\mathrm{Bu}$ sistem sadece ortamdan etileni absorbe etmekle kalmamakta, aynı zamanda benzen, toluen ve ksilen gibi diğer organik bileşikleri de absorbe edebilmektedir (Ozdemir ve Floros, 2004). Bu sistemlere ek olarak; paladyumun, yüksek bağıl nem durumlarında permanganat bazlı tutuculardan daha yüksek bir etilen tutucu kapasitesine sahip olduğu tespit edilmiştir. Kömür ile paladyum kullanımı etilen birikimini önlemede etkili bulunmuştur (Pereira de Abreu ve ark., 2012).

Etilen tutucuların meyve ve sebzelerdeki uygulamalarına bakıldığında, Abe ve Watada (1991) tarafından gerçekleştirilen çalışmada, etilen tutucu olarak paladyum klorür ile birlikte kullanılan kömürün, taze kesilmiş muzlarda etilen üretimini yavaşlatarak, yumuşamayı azalttığı ve $20^{\circ} \mathrm{C}$ sıcaklıkta 3 günlük depolama sırasında etilen gazının çoğunun emilmesinde etkili olduğu tespit edilmiştir. Diğer bir çalışmada ise paladyumla modifiye edilmiş zeolitin muzun olgunlaşmasını geciktirdiği, sertliğini ve meyvenin kabuk rengini önemli ölçüde koruduğu saptanmıştır (Tzeng ve ark., 2019). Kaewklin ve ark. (2018) tarafindan, domateslerinin kalitesini korumak amacıyla geliştirilen nano- $\mathrm{TiO}_{2}$ ile birleştirilmiş kitosan bazlı etilen tutucu filmlerin, etilenin fotokalitik degradasyona uğramasını sağladığı ve domatesin saklama süresini uzattığı tespit edilmiştir. Kivilerde de olgunlaşma sürecinin potasyum permanganat bazlı etilen tutucularla geciktirilerek, sertlik kaybının, klorofil parçalanmasının ve titrasyon asitliğinin korunmasının sağlandığ 1 belirlenmiştir (Bal ve Celik, 2010).

Etilen tutucuların taze ürünlerin kalitesini korumada etkili olduğu çalışmalarla gösterilse de, güvenlik endişeleri ve sınırlamaları dikkate alınmalıdır. Öncelikle, saket formunda kullanılan tutucular üzerine gerekli uyarılar eklenerek, tüketiciler tarafından yanlışlıkla tüketilmesinin önüne geçilmelidir. Özellikle $\mathrm{KMnO}_{4}$ kullanıldığında migrasyon olasılığı düşünülerek, gerekli testlerin yapılması gerekmektedir. Son olarak ise etilen tutucu ambalajlamanın yaratacağı maliyet göz önüne alınarak, tüketici tarafından bu maliyet artışının kabul edilebilirliği araştırılmalıdır (Gaikwad ve ark., 2020).

\subsection{Nem Düzenleyiciler}

Gıda ambalajlarındaki aşırı nemin kontrolü, üründeki mikrobiyal büyümeyi baskılamak ve ambalaj filmi üzerindeki buğulanmayı önlemek için önemlidir (Gavara ve ark., 2009). Eğer ambalajın nem buharı geçirgenliği düşükse, ambalajın içindeki nem birikimi daha belirgin konuma gelmektedir. Bir gida ambalaj1 içinde oluşan nem, genellikle taze ürünün solunumu ve sıcaklık dalgalanmaları nedeniyle oluşabilmektedir (Ozdemir ve Floros, 2004). Eğer bu nem ortamdan uzaklaştırılmazsa, bu nem ürün tarafından emilmekte veya yoğuşma oluşmakta ve mikrobiyal bozulmaya ve/veya düşük tüketici çekiciliğine neden olmaktadır (Vermeiren ve ark., 1999). Bu tür uygulamalarda, antifog adı verilen katkılar ambalaj filmine eklenerek, yoğunlaşmış su ile film arasındaki yüzey gerilim azaltılmaktadır. Bu durum, filmin şeffaflığına katkıda bulunmakta ve tüketicilerin ambalajlanmış gıdaları net bir şekilde görmesine izin vermektedir. Ancak, bu katkılar ambalaj içinde bulunan su miktarını etkilememektedir (Pereira de Abreu ve ark., 2012). İşte gıdalarda nem dolayısıyla gerçekleşen istenmeyen reaksiyonları önlemek ve tepe 
boşluğunda istenen bağıl nemi sağlamak için, uygun nem buharı geçirgenliğine sahip bir film kullanabilmekte veya nem düzenleyici bileşenlerden yararlanılabilmektedir. Ambalaj içi nemin düzenlenmesinde silika jel, doğal kil (montmorillonit), kalsiyum oksit, kalsiyum klorür ve modifiye nişasta gibi çeşitli nem tutuculardan yararlanılmaktadır (Bodbodak ve Rafiee, 2016). Nem tutma özeliğindeki bu bileşenler, iki veya daha fazla mikro gözenekli polimerik malzeme katmanından oluşan pedlerde bulunabileceği gibi, saket formunda da kullanılabilmektedir (Vermeiren ve ark., 1999). Nem düzenleyici türünün seçimi; gıdanın boyutuna ve ağırlığına ve başlangıçtaki su aktivitesine, ambalajın su buharı geçirgenlik özelliğine, depolama sıcaklığı ve nemine, gıdanın neme duyarlılığına ve istenilen raf ömrüne bağlı olarak değişmektedir (Pereira de Abreu ve ark., 2012).

Nem düzenleyicilerin meyve ve sebzelerdeki uygulamalarına bakıldığında; Shirazi ve Cameron (1992) tarafindan yapılan çalışmada $20^{\circ} \mathrm{C}$ 'de $\mathrm{NaCl}$ içeren bir saket ile ambalajlanmış domateslerin raf ömrü, esas olarak yüzeyde küf büyümesinin gecikmesi nedeniyle 5 günden, 15-17 güne kadar uzatılmıştır. Diğer bir çalışmada (Bovi ve ark., 2018), çilekler paket içerisindeki nemin düzenlenmesi amacıyla fruktoz içeren film ile ambalajlanmıştır. Sonuçlara göre ambalaj içerisinde yoğunlaşma minimum düzeyde gerçekleşmiş ve ağırlık kaybı da \% 1 değerinin altına çekilmiştir. Etilen tutucu ve nem düzenleyicinin (sorbitol) birlikte brokoli ambalajlarında kullanıldığı çalışmada (DeEll ve ark., 2006), sorbitolün MAP ile kullanılmasının, brokolilerde daha iyi görünüş ve sertlik sağladığı bu nedenle kaliteyi koruyarak, pazarlanabilirlik sürecini artırdığı belirlenmiştir. Mantarlarda nem düzenleyici olarak kullanılan sorbitolün raf ömrünü artırdığı ancak yüksek sorbitol miktarlarının ise ağırlık kaybını yükselttiği tespit edilmiştir (Roy ve ark., 1995).

Nem tutucular genel olarak değerlendirildiğinde, organik bazlı olanların maliyetinin yüksek ve tutucu kapasitesinin ise inorganik bazlılara göre düşük olduğu bildirilmektedir. $\mathrm{Bu}$ nedenle istenen etkinin sağlanması için büyük saket şeklinde kullanılması çeşitli problemler oluşturabilmektedir. Ayrıca saket biçiminde kullanılan materyallerin ambalajlanmış gıdanın bazı bileşimsel ve duyusal özelliklerini de etkileme potansiyeli bulunduğundan dikkatli seçilmesi gerekmektedir (Gaikwad ve ark., 2019).

\subsection{Antimikrobiyal Bileșenler}

Gıda güvenliği ve gıda kalitesi; gıda sanayisi, hükümetler ve tüketiciler için endişe yaratan başlıca konulardandır. Gıdaların bozulmasına neden olan faktörlerden en önemlisi olan mikrobiyal bozulma hem ürünün genel kalitesine ve hem de tüketici güvenliğine zarar vermektedir. Çünkü, bazı mikroorganizmalar ve toksinleri ciddi gıda kaynaklı salgınlara neden olabilmektedir (Aksoy, 2020). Gidalarda kontaminasyon, su ve toprak kaynaklı olabileceği gibi, taşıma ve ürünün işlenmesi sırasında da meydana gelebilmektedir (Recep ve ark., 2019). Hasat sonrası meydana gelen bulaşılar, en fazla taze meyve sebze gibi pişmemiş gıdalarda daha fazla risk oluşturmaktadır (Sağdıç ve ark., 2020). Bu nedenle gıdaların bozulmasını önlemek ve gıda raf ömrünü uzatmak için çeşitli tedbirler geliştirilmektedir. Bu tedbirlerden bir tanesi ise, ambalaj materyalinin mikrobiyal büyümeyi geciktirmek ve koruyucu bir bariyer oluşturmak üzere antimikrobiyallerle güçlendirilmesidir (Corrales ve ark., 2014). Bu kapsamda çeşitli yabani bitkilerden ve baharatlarden elde edilen ve bakteri, fungus ve virüslere karş1 etkisi tespit edilen birçok bileşen bulunmaktadır (Akarca ve Tomar, 2019; Tomar ve Akarca, 2019). Bu bileşenlere örnek olarak tarçın, kırmızı biber, karanfil, kekik, biberiye, kekik, soğan ve sarımsak gibi gıdalardan elde edilen özler verilebileceği gibi, fungal veya bakteri kaynaklı olan nisin, natamisin, pediosin ve çeşitli bakteriyosinler de bulunabilmektedir (Biji ve ark., 2015). Antimikrobiyal ambalajlama olarak adlandırılan bu teknik; a)Antimikrobiyal ajan içeren saket veya pedlerin ambalaj içerisine yerleştirilmesiyle, b)Uçucu veya uçucu olmayan antimikrobiyallerin polimerlere yedirilmesiyle, c)Antimikrobiyallerin polimer yüzeyine tutturulması veya kaplanmasıyla, d)Antimikrobiyallerin polimerlere iyon veya kovalent bağlarla immobilizasyonuyla veya e)Doğası gereği antimikrobiyal özellik gösteren polimerlerin kullanılmasıyla sağlanmaktadır (Appendini ve Hotchkiss, 2002).

$\mathrm{Bu}$ yöntemlerin ilki olan saketlerin kullanımı; gıda kaynaklı mikroorganizmalara karşı iyi antimikrobiyal aktivitelere sahip uçucu bileşiklerin saketlere dahil edilmesi ve ardından salınması yoluyla gerçekleşmektedir. Saketlere dahil edilen antimikrobiyal bileşikler arasında etanol, klor dioksit ve çeşitli bitki esansiyel yağları ve bunların ana aktif bileşenleri yer almaktadır. Saketlere benzer şekilde, antimikrobiyal olarak aktif bileşenlerin emici pedlerde kullanımı konusunda da çalışmalar bulunmaktadır (Otoni ve ark., 2016). Gaz formunda kullanılan antimikrobiyal bileşenlerin uçucu özelliği sebebiyle gıdanın tüm yüzeyine temas etmesi, ürünlerdeki etkinliğini daha da artırmaktadır (Harun ve Çetin, 2018).

İkinci yöntem olarak kullanılan, antimikrobiyallerin polimerlere yedirilmesinde; nisin, sorbat, glukoz oksidaz, propiyonik, benzoik asit ve gümüş gibi bileşenlerden yararlanılmaktadır (Hotchkiss, 1997). Bu bileşenlerden gıda katkı maddesi olarak da kabul edilen nisin, en önemli bakteriyosinlerden bir tanesi olup, birçok bakteriyi inhibe ederek, gıdaların raf ömrünün artırılmasında kullanılmaktadır (Demirgül ve Sağdıç, 2017). Antimikrobiyallerin polimerlere yedirilmesiyle özellikle gıda yüzeyindeki bozulmaların önlenmesi amaçlanmaktadır. Bu yaklaşımla birlikte gıdalara eklenen antimikrobiyallerin de azaltılması sağlanabilmektedir (Appendini ve Hotchkiss, 2002). Fakat, polimerlere aktif maddelerin dahil edilmesi polimer kimyasını değiştirerek oksijen geçirgenliği, çekme mukavemeti ve salınım gibi özellikleri değiştirmektedir (Balasubramanian ve ark., 2009).

Antimikrobiyallerin polimer yüzeyine tutturulması veya kaplanmasında ise genellikle polimer işlemede kullanılan sıcaklıkları tolere edemeyen bileşikler kullanılmaktadır. $\mathrm{Bu}$ bileşenlerden; ambalaj yüzeyine mikrobiyal kontaminantların yapışmasını önlemek veya tam tersi olarak da eğer yapışma gerçekleştiyse onları yüzeyden uzaklaştırmak amacıyla yararlanılmaktadır. Protein bileşiklerin yüzeylerde oldukça aktif olması nedeniyle nisin gibi bileşenler yüzey kaplanmasında önemli yer tutmaktadır (Daeschel ve ark., 1992).

Antimikrobiyallerin polimerlere iyon veya kovalent bağlarla immobilizasyonunda, hem polimerlerde hem de kullanılan antimikrobiyallerde fonksiyonel grupların bulunması zorunludur. Fonksiyonel gruplara sahip antimikrobiyallere örnek olarak peptitler, enzimler, poliaminler ve organik asitler verilebilmektedir. Fonksiyonel gruplara ek olarak, bu yöntemde polimer yüzeyini biyoaktif maddeye bağlayan çeşitli moleküllerin kullanımı da gerekebilmektedir. Bu moleküller yeterli hareket serbestliğine izin vererek, antimikrobiyal bileşenlerin aktif kısmının gıda yüzeyindeki mikroorganizmalarla temas etmesini sağlamaktadır (Appendini ve Hotchkiss, 2002).

Antimikrobiyal ambalajlamanın uygulanmasında son yöntem ise doğası gereği antimikrobiyal özellik gösteren polimerlerin 
kullanılmasıdır. Antimikrobiyal polimerler, bir yüzeyde veya onu çevreleyen ortamda mikroorganizmaların büyümesini inhibe edebilen malzemelerdir. Kitosan, dördüncül azot grupları içeren bileşikler ve halaminler, antimikrobiyal aktivite gösterme konusunda doğal bir kapasiteye sahip bileşenlere örnek olarak verilebilmektedir (Jain ve ark., 2014). Bu bileşenler arasında en fazla çalışılan materyal olan kitosan, kabuklu deniz hayvanlarından elde edilmekte olup, molekül ağırlığı veya polimerizasyon derecesine göre farklı özellikler göstermektedir (Demirci ve ark., 2017).

Antimikrobiyal bileşiklerin meyve ve sebzelerdeki uygulamalarına bakıldığında, Popa ve ark. (2007) tarafından gerçekleştirilen araştırmada, yaban mersini ambalajlarında saket şeklinde kullanılan klor dioksitin, mezofilik aerobik bakteri, koliform, E.coli, maya ve küf sayısını inhibe etmede başarılı olduğu bulunmuştur. Li ve ark. (2017) tarafindan yapılan çalışmada ise $\mathrm{ZnO}$ nanopartikülleri antimikrobiyal amaçlı polilaktik asit matriksine dahip edilip taze kesilmiş elmalardaki etkinliği incelenmiştir. Sonuçlara göre bu ambalaj materyalinin, elmanın sertlik, toplam fenolik içerik ve rengini koruduğu, ayrıca toplam bakteri ve maya küf sayısını azaltmada etkili olduğu tespit edilmiştir. Çinko oksitin ayrıca E. Coli üzerinde de inhibe edici etkisi bulunmasına rağmen, bu bileşiğin ağır metal grubuna girmesi nedeniyle, sağlık açısından potansiyel olumsuz etkilerinin daha detaylı incelenmesi gerekmektedir (Esmeray ve Özata, 2019). Patateslerin ambalajlanmasında kullanılan şirink film üzerine kaplanan silikon dördüncül amonyum tuzlarının depolama sırasında olumlu veya olumsuz bir etkisi görülmemiş fakat ambalajlama öncesi patateslerin \% 0.5 sodyum hipoklorit çözeltisine daldırılmasının hastalıkları azalttığı tespit edilmiştir (Shetty ve Dwelle, 1990). Kitosanın antimikrobiyal etkisinin dilimlenmiş mango meyvesinde araştırıldığı çalışmada, kontrol grubuna göre kitosanın toplam canlı sayısını azaltmada etkili olduğu saptanmıştır. Ayrıca kitosan konsantrasyonunun artmasının inhibe ediciliği değiştirmediği belirlenmiştir (Chien ve ark., 2007). Taze kesilmiş mantarlar üzerine kitosanın etkisinin incelendiği diğer bir çalışmada ise kitosan konsantrasyonunun artmasıyla küf ve maya sayısında azalmanın daha belirginleştiği rapor edilmiştir (Eissa, 2007).

Antimikrobiyal ambalajlamada karşılaşılan en önemli zorluklardan bir tanesi mikrobiyal büyüme kinetiği ile kontrollü salınım hızı arasındaki dengenin kurulmasıdır. Ayrıca salınan antimikrobiyal ajanın konsantrasyonun seçimi de önemlidir. Ĕger düşük olursa istenen etki görülememekte, yüksek olursa ise duyusal veya toksikolojik özellikler bakımından olumsuzluklar yaşanabilmektedir (Mousavi Khaneghah ve ark., 2018). Bunun yanında, antimikrobiyal ajanların polimere doğrudan eklenmesi ise ekstrüzyon gibi yüksek sıcaklıklarda, salınım hızını ve aktif ajanların stabilitesini etkilemektedir. Polimerlere eklenen dolgu maddeleri, buğu önleyiciler, antistatik maddeler, kayganlaştırıcılar, stabilizatörler ve plastikleştiriciler de antimikrobiyal polimerlerin aktivitesini olumsuz etkileyebilmektedir (Appendini ve Hotchkiss, 2002). Bu nedenle, iyi bir antimikrobiyal ambalaj tasarımı için; doğru antimikrobiyal ajanın doğru ambalaj materyali ve gıda için seçilmesi gerekmektedir. Bu sayede; ambalaj ile gida arasında iyi bir etkileşim sağlanarak, istenilen düzeyde bir antimikrobiyal salınım gerçekleşebilecektir (Quintavalla ve Vicini, 2002).

\section{Tüketicinin Aktif Ambalajlamaya Bakışı ve Yasal Düzenlemeler}

Yeni ambalajlama teknolojileri, tüketici taleplerine ve endüstri eğilimlerine tatmin edici yanıtlar veren çözümler üretmektedir. Fakat sağladıkları bir çok faydaya rağmen, bu tür teknolojilerin gıda ürünlerinde tam ölçekli olarak benimsenmesi ve uygulanmasının önünde ambalaj bileşenlerinin gıda ile temasının uygunluğu, çevresel sürdürülebilirlik ve özellikle tüketiciler tarafından kabul edilebilirliği bakımından çeşitli sorunlar bulunmaktadır (Li ve ark., 2020). Çünkü tüketicilerin kafalarında, kullanılan bileşenlerin zararlı olup olmadığı konularında endişeler yer almaktadır (Bodbodak ve Rafiee, 2016). Bununla birlikte, yenilikçi konseptleri kabul etme söz konusu olduğunda tüketiciler bazen tutucu olabilmektedir. Ayrıca tüketicilerin herhangi yeni bir teknolojiye yönelik görüşü heterojen olabilmekte ve tutumlar, teknolojinin özelliklerine, teknoloji neofobisinin düzeyine veya tüketicinin diğer teknolojilerle olan ilişkilerine bağlı olarak değişebilmekte, bu nedenle farklı teknolojiler farklı tepkiler alabilmektedir $\left(\mathrm{O}^{\prime}\right.$ Callaghan ve Kerry, 2016). Aktif ve akıllı ambalajlamanın tüketici tarafından kabulü konusunda yapılan çalışmada, Türkiye'deki tüketicilerin çoğunun mikrobiyal bozulmayı önlemek için yenilikçi ambalajlama uygulamalarını kullanmak istediği fakat saket biçimde kullanılan aktif bileşenlerin yanlışlıkla tüketilebilme ihtimali nedeniyle istenmediği saptanmıştır. Ayrıca tüketicilerin, kullanılan yenilikçi ambalajların pozitif etkilerinin görülmesi halinde \% 10'a kadar bir fiyat artışını kabul edebilecekleri belirtilmiştir. Son olarak ise tüketiciler çeşitli vasıtalarla gerçekleştirilecek bilgilendirici faaliyetlerin yenilikçi ambalajların tüketiciler tarafından kabul edilebilirliğini artıracağını bildirmişlerdir (Aday ve Yener, 2014). Mikkola ve ark. (1997) tarafından yapılan çalışmada ise tüketicilerin \% 72'sinin g1da ambalajlarında kullanılan oksijen saketlerine olumlu baktığı bildirilmiştir. Aynı tüketicilerin \% 40'^nın oksijen tutucu içeren ambalajlara 10 peni daha fazla verebileceği saptanmıştır. Slovak tüketiciler üzerine (Loucanova ve ark., 2017) tarafından yapılan çalışmada 41-50 yaş arasındaki tüketicilerin aktif ve akıllı ambalajlama konusunda hedef segment olduğu ve bu yaş aralığının yukarısındaki tüketicilerin aktif ambalajlama fonksiyonlarına daha önem verirken, aynı yaş aralığının altındaki tüketicilerin ise akıllı ambalajlamaya önem verdiği saptanmıştır. Roberts, (2003) tarafindan gerçekleştirilen çalışmada ise tüketicilerin ambalaj filmlerine yedirilen aktif bileşenleri, saket teknolojisine göre daha fazla tercih ettiği, ayrıca Avrupadaki tüketicilerin Japon tüketicilere göre saket teknolojisine olan direncinin daha fazla olduğu tespit edilmiştir. Barska ve Wyrwa (2016) tarafından Polonyalı tüketiciler üzerine yapılan ankette ise, aktif ambalajlama teriminin sadece \% 4'lük bir kısım tarafından bilindiği, \% 68'lik bir kısmın ise geçerli tanım verildikten sonra aktif ambalajlama teknolojisi kullanılan gıdaları tüketmek istediği saptanmıştır. Çinli tüketicilerin aktif ve akıllı ambalajlama teknolojilerine bakış açısının incelendiği çalışmada (Li ve ark., 2020) ise, günümüzde geçerli olan ambalajlama teknolojilerinin tüketici memnuniyetini sağlamada yetersiz olduğu belirlenmiştir. Ayrıca çalışmaya katılan tüketicilere aktif ve akıllı ambalaj teknolojilerine bakış açıları sorulduğunda, yarısının bu teknolojileri kabul edilebilir bulduğu saptanmıştır.

Yasal düzenlemeler açısından bakıldığında ise Avrupa Birliği ülkelerinde aktif ve akıllı ambalaj uygulamaları (EC) 1935/2004 ve 450/2009 yönetmelikleriyle düzenlenmiştir. Bu yönetmeliklere göre (Pereira de Abreu ve ark., 2012); 
- Kullanılan bileșenler amaçlanan hedefler için etkili ve uygun olmalidir.

- Kullanılan bileşenler iyi üretim uygulamalarına uygun olarak üretilmeli ve insan sağlığına zararsız olmalıdır. Ayrıca gıdanın bileşimi veya duyusal özelliklerinde değişime neden olmamalıdır.

- Kullanılan bileşenlerin etiketlenmesi, gösterimi veya reklamı tüketiciyi yanıltmamalı ve bu bileşenler gıdanın bozulması durumunda meydana gelen değişimleri maskelememelidir.

- Gidayla temasta olmaması durumunda bile, aktif bileşen tarafından salınan bileşiğin ismi ve miktarı belirtilmelidir.

- Sadece bu konuda izin verilen maddeler kullanılmalı, bu bileşenler mutajenik, karsinojenik veya toksik olmamalıdir.

- Tüketicinin yememesi için bu bileşenlerin üzerine "YENILLMEZ" ibaresi eklenmeli ve bu ibare görülebilir olmalıdır (Pereira de Abreu ve ark., 2012).

\section{Sonuç}

Geleneksel ambalajlama teknolojilerinin gidaların kalite özelliklerini koruma ve raf ömrünü uzatma konusunda yetersiz kalması nedeniyle, tüketiciler gıda güvenliğini daha iyi sağlayan etkili ambalajlama teknolojilerine yönelmektedir. $\mathrm{Bu}$ teknolojilerden bir tanesi olan aktif ambalajlamada kullanılan oksijen, karbondioksit ve etilen tutucular, nem düzenleyiciler ve antimikrobiyal bileşenler gıdaların besinsel ve duyusal kalitesini korumakta ayrica patojenik ve bozulma etmeni olan mikroorganizmaları da inhibe etmektedir. Bununla birlikte ambalaj filmlerinde bu bileşenlerden yararlanmak, gida güvenliğini sağlama amaçlı kullanılan katkı maddelerin kullanımını da azaltmak için yeni bir yaklaşım sunmaktadır. Özellikle taze meyve ve sebzeler gibi birçok fizyolojik (solunumterleme), kimyasal (oksidasyon) ve mikrobiyolojik proseslerden etkilenen ürün gruplarında bu teknolojinin kullanılmasıyla gıdalar daha uzun mesafelere ulaştırılabilecek ve perakende noktalarında daha uzun süre bozulmadan kalabilecektir.

\section{Kaynakça}

Abe, K., \& Watada, A.E. (1991). Ethylene absorbent to maintain quality of lightly processed fruits and vegetables. Journal of Food Science, 56(6), 1589-1592.

Açışlı, Ö. (2019). Doum palm meyve kabuklarından aktif karbon üretimi ve karakterizasyonu. Avrupa Bilim ve Teknoloji Dergisi, 16, 544-551.

Aday, M.S., \& Caner, C. (2013). The shelf life extension of fresh strawberries using an oxygen absorber in the biobased package. LWT-Food Science and Technology, 52(2), 102-109.

Aday, M.S., Caner, C., \& Rahvalı, F. (2011). Effect of oxygen and carbon dioxide absorbers on strawberry quality. Postharvest Biology and Technology, 62(2), 179-187.

Aday, M.S., \& Yener, U. (2014). Understanding the buying behaviour of young consumers regarding packaging attributes and labels. International Journal of Consumer Studies, 38(4), 385-393.

Ahmed, I., Lin, H., Zou, L., Brody, A.L., Li, Z., Qazi, I.M., Pavase, T.R., \& Lv, L. (2017). A comprehensive review on the application of active packaging technologies to muscle foods. Food Control, 82, 163-178.
Akarca, G., \& Tomar, O. (2019). Afyonkarahisar ili çevresinde yetişen ve halk tarafından tüketilen bazı yabani bitkilerin antioksidan ve antimikrobiyal etkileri. Avrupa Bilim ve Teknoloji Dergisi(15), 259-268.

Aksoy, A. (2020). Gıda endüstrisinde elektrolize su kullanımı. Avrupa Bilim ve Teknoloji Dergisi, 19, 254-262.

An, D.S. (2016). Effect of active master packaging system on preservation of fresh shiitake mushrooms in supply chain. Journal of the Korean Society of Food Science and Nutrition, 45(3), 402-408.

Appendini, P., \& Hotchkiss, J.H. (2002). Review of antimicrobial food packaging. Innovative Food Science \& Emerging Technologies, 3(2), 113-126.

Bal, E., \& Celik, S. (2010). The effects of postharvest treatments of salicylic acid and potassium permanganate on the storage of kiwifruit. Bulg. J. Agric. Sci, 16(2), 576-584.

Balasubramanian, A., Rosenberg, L.E., Yam, K.I.T., \& Chikindas, M.L. (2009). Antimicrobial packaging: potential vs. realitya review. Journal of Applied Packaging Research, 3(4), $193-$ 221.

Barska, A., \& Wyrwa, J. (2016). Consumer perception of active intelligent food packaging. Problems of Agricultural Economics, 4(349), 138-159.

Biji, K.B., Ravishankar, C.N., Mohan, C.O., \& Gopal, T.K.S. (2015). Smart packaging systems for food applications: a review. Journal of Food Science and Technology, 52(10), 6125-6135.

Bodbodak, S., \& Rafiee, Z. (2016). Recent trends in active packaging in fruits and vegetables. In: Eco-friendly technology for postharvest produce quality, M. W. Siddiqui (Eds.), Elsevier, New York, 77-125.

Bovi, G.G., Caleb, O.J., Klaus, E., Tintchev, F., Rauh, C., \& Mahajan, P.V. (2018). Moisture absorption kinetics of FruitPad for packaging of fresh strawberry. Journal of Food Engineering, 223, 248-254.

Brody, A.L., Bugusu, B., Han, J.H., Sand, C.K., \& McHugh, T.H. (2008). Innovative food packaging solutions. Journal of Food Science, 73(8), 107-116.

Brody, A.L., Strupinsky, G.R., \& Pruskin, L.R. (1995). The use of oxygen scavengers and active packaging to reduce oxygen within internal package environments. U.S. Army Soldier Systems Command Technical Report, 1-124.

Charles, F., Guillaume, C., \& Gontard, N. (2008). Effect of passive and active modified atmosphere packaging on quality changes of fresh endives. Postharvest Biology and Technology, 48(1), 22-29.

Charles, F., Rugani, N., \& Gontard, N. (2005). Influence of packaging conditions on natural microbial population growth of endive. Journal of Food Protection, 68(5), 1020-1025.

Charles, F., Sanchez, J., \& Gontard, N. (2003). Active modified atmosphere packaging of fresh fruits and vegetables: modeling with tomatoes and oxygen absorber. Journal of Food Science, 68(5), 1736-1742.

Chien, P.J., Sheu, F., \& Yang, F.H. (2007). Effects of edible chitosan coating on quality and shelf life of sliced mango fruit. Journal of Food Engineering, 78(1), 225-229.

Corrales, M., Fernández, A., \& Han, J.H. (2014). Antimicrobial Packaging Systems. In: Innovations in Food Packaging J. H. Han (Eds.), Academic Press, San Diego, 133-170.

Çağlar, M., \& Demirci, M. (2018). Üzümsü meyvelerde bulunan fenolik bileşikler ve beslenmedeki önemi. Avrupa Bilim ve Teknoloji Dergisi, 7(11), 18-26. 
Daeschel, M.A., McGuire, J., \& Al-Makhlafi, H. (1992). Antimicrobial activity of nisin adsorbed to hydrophilic and hydrophobic silicon surfaces. Journal of Food Protection, 55(9), 731-735.

Dainelli, D., Gontard, N., Spyropoulos, D., Zondervan-van den Beuken, E., \& Tobback, P. (2008). Active and intelligent food packaging: legal aspects and safety concerns. Trends in Food Science \& Technology, 19, S103-S112.

Day, B.P.F., \& Potter, L. (2011). Active packaging. Food beverage packaging technology, 251-262.

DeEll, J.R., Toivonen, P.M.A., Cornut, F., Roger, C., \& Vigneault, C. (2006). Addition of sorbitol with $\mathrm{KMnO}_{4}$ improves broccoli quality retention in modified atmosphere packages. Journal of Food Quality, 29(1), 65-75.

Demirci, M., Sağdıç, O., Çavuş, M., Pehlivanoğlu, H., Yilmaz, M.T., \& ÇağLar, M. (2017). Prebiyotik oligosakkaritlerin kaynakları, üretimleri ve gida uygulamaları. Avrupa Bilim ve Teknoloji Dergisi, 6(10), 20-31.

Demirgül, F., \& Sağdıç, O. (2017). Laktik starter kültür üretim teknolojisi. Avrupa Bilim ve Teknoloji Dergisi, 7(11), 27-37.

Demirgül, F., \& Sağdıç, O. (2018). Fermente süt ürünlerinin insan sağlı̆̆ına etkisi. Avrupa Bilim ve Teknoloji Dergisi, 13, 45-53.

Eissa, H.A.A. (2007). Effect of chitosan coating on shelf life and qaulity of fresh cut mushroom. Journal of Food Quality, 30(5), 623-645.

Esmeray, E., \& Özata, O. (2019). Nanopartiküllerin çevre mühendisliğinde kullanımı ve temel laboratuvar malzemeleri ile gümüş nanopartikül (AgNPs) sentezi. Avrupa Bilim ve Teknoloji Dergisi, 16, 521-527.

Gaikwad, K.K., Singh, S., \& Ajji, A. (2019). Moisture absorbers for food packaging applications. Environmental Chemistry Letters, 17(2), 609-628.

Gaikwad, K.K., Singh, S., \& Lee, Y.S. (2018). Oxygen scavenging films in food packaging. Environmental Chemistry Letters, 16(2), 523-538.

Gaikwad, K.K., Singh, S., \& Negi, Y.S. (2020). Ethylene scavengers for active packaging of fresh food produce. Environmental Chemistry Letters, 1-16.

Galić, K., Ščetar, M., \& Kurek, M. (2011). The benefits of processing and packaging. Trends in Food Science \& Technology, 22(2-3), 127-137.

Garipoğlu, G. (2019). Enzime dirençli nişasta kullanarak fonksiyonel galeta geliştirilmesi. Avrupa Bilim ve Teknoloji Dergisi, 15, 375-380.

Gavara, R., Catalá, R., \& Hernández-Muñoz, P. (2009). Extending the shelf-life of fresh-cut produce through active packaging. Stewart Postharvest Review, 5(4), 1-5.

Han, J.H. (2014). A review of food packaging technologies and innovations. In: Innovations in food packaging, S. L. Taylor (Eds.), Elsevier, New York, 3-12.

Han, J.W., Ruiz-Garcia, L., Qian, J.P., \& Yang, X.T. (2018). Food packaging: A comprehensive review and future trends. Comprehensive Reviews in Food Science and Food Safety, 17(4), 860-877.

Harun, U., \& Çetin, B. (2018). Etil pirüvat buharının tavuk etinin raf ömrü üzerine etkisi. Avrupa Bilim ve Teknoloji Dergisi, 14, 255-260.

Hotchkiss, J.H. (1997). Food-packaging interactions influencing quality and safety. Food Additives \& Contaminants, 14(6-7), 601-607.

Huang, W.H., Hsu, C.K., \& Chiang, B.H. (1999). Formulations of controlled atmosphere agents for packaged foods. Journal of Agricultural and Food Chemistry, 47(3), 906-910.
Hurme, E., Thea, S.M., Ahvenainen, R., \& Nielsen, T. (2002). Active and intelligent packaging. In: Minimal Processing Technologies in the Food Industries, T. Ohlsson \& N. Bengtsson (Eds.), Woodhead New York, 87-123.

Jain, A., Duvvuri, L.S., Farah, S., Beyth, N., Domb, A.J., \& Khan, W. (2014). Antimicrobial Polymers. Advanced Healthcare Materials, 3(12), 1969-1985.

Kaewklin, P., Siripatrawan, U., Suwanagul, A., \& Lee, Y.S. (2018). Active packaging from chitosan-titanium dioxide nanocomposite film for prolonging storage life of tomato fruit. International Journal of Biological Macromolecules, 112, 523-529.

Kartal, S., Aday, M.S., \& Caner, C. (2012). Use of microperforated films and oxygen scavengers to maintain storage stability of fresh strawberries. Postharvest Biology and Technology, 71, 32-40.

Lee, D.S. (2016). Carbon dioxide absorbers for food packaging applications. Trends in Food Science \& Technology, 57, 146155.

Lelièvre, J.M., Latchè, A., Jones, B., Bouzayen, M., \& Pech, J.C. (1997). Ethylene and fruit ripening. Physiologia plantarum, 101(4), 727-739.

Li, T., Lloyd, K., Birch, J., Wu, X., Mirosa, M., \& Liao, X. (2020). A quantitative survey of consumer perceptions of smart food packaging in China. Food science \& nutrition, 8(8), 39773988.

Li, W., Li, L., Cao, Y., Lan, T., Chen, H., \& Qin, Y. (2017). Effects of PLA film incorporated with $\mathrm{ZnO}$ nanoparticle on the quality attributes of fresh-cut apple. Nanomaterials, 7(8), 207.

Lopez-Rubio, A., Almenar, E., Hernandez-Muñoz, P., Lagarón, J.M., Catalá, R., \& Gavara, R. (2004). Overview of active polymer-based packaging technologies for food applications. Food Reviews International, 20(4), 357-387.

Loucanova, E., Kalamarova, M., \& Parobek, J. (2017). The Innovative Approaches to Packaging - Comparison Analysis of Intelligent and Active Packaging Perceptions in Slovakia. Studia Universitatis Vasile Goldis Arad-Economics Series, 27(2), 33-44.

Mikkola, V., Lähteenmäki, L., Hurme, E., Heiniö, R.L., JärviKääriäinen, T., \& Ahvenainen, R. (1997). Consumer attitudes towards oxygen absorbers in food packages: Technical Research Centre of Finland Espoo.

Mousavi Khaneghah, A., Hashemi, S.M.B., \& Limbo, S. (2018). Antimicrobial agents and packaging systems in antimicrobial active food packaging: An overview of approaches and interactions. Food and Bioproducts Processing, 111, 1-19.

Nugraha, B., Bintoro, N., \& Murayama, H. (2015). Influence of $\mathrm{CO}_{2}$ and $\mathrm{C}_{2} \mathrm{H}_{4}$ Adsorbents to the Symptoms of Internal Browning on the Packaged 'Silver Bell' Pear (Pyrus communis L.). Agriculture and Agricultural Science Procedia, 3, 127-131.

O’ Callaghan, K.A.M., \& Kerry, J.P. (2016). Consumer attitudes towards the application of smart packaging technologies to cheese products. Food Packaging and Shelf Life, 9, 1-9.

Otoni, C.G., Espitia, P.J.P., Avena-Bustillos, R.J., \& McHugh, T.H. (2016). Trends in antimicrobial food packaging systems: Emitting sachets and absorbent pads. Food Research International, 83, 60-73.

Ozdemir, M., \& Floros, J.D. (2004). Active food packaging technologies. Critical Reviews in Food Science and Nutrition, 44(3), 185-193. 
Pereira de Abreu, D.A., Cruz, J.M., \& Paseiro Losada, P. (2012). Active and intelligent packaging for the food industry. Food Reviews International, 28(2), 146-187.

Popa, I., Hanson, E.J., Todd, E.C.D., Schilder, A.C., \& Ryser, E.T. (2007). Efficacy of chlorine dioxide gas sachets for enhancing the microbiological quality and safety of blueberries. Journal of Food Protection, 70(9), 2084-2088.

Prasad, P., \& Kochhar, A. (2014). Active packaging in food industry: a review. Journal of Environmental Science, Toxicology and Food Technology, 8(5), 1-7.

Quintavalla, S., \& Vicini, L. (2002). Antimicrobial food packaging in meat industry. Meat Science, 62(3), 373-380.

Recep, K., Acaröz, U., Gürler, Z., Soylu, A., \& Küçükkurt, O. (2019). Taze marul örneklerinde Escherichia coli $O 157$ ve Listeria monocytogenes varlı̆̆ının belirlenmesi. Avrupa Bilim ve Teknoloji Dergisi, 16, 870-873.

Roberts, R. (2003). Consumer attitudes and future market trends for active \& intelligent packaging. Actipak unwraps Europe Conference, 23-26.

Rooney, M.L. (1995). Overview of active food packaging. In: Active food packaging, M. L. Rooney (Eds.), Springer, Boston, 1-37.

Roy, S., Anantheswaran, R.C., \& Beelman, R.B. (1995). Sorbitol increases shelf life of fresh mushrooms stored in conventional packages. Journal of Food Science, 60(6), 1254-1259.

Sağdıç, O., Kayacan, S., Dertli, E., \& Arici, M. (2020). Gıda güvenliği açısından COVID-19 etmeni SARS-CoV-2'nin değerlendirilmesi ve korunma yöntemleri. Avrupa Bilim ve Teknoloji Dergisi, 18, 927-933.

Scully, A.D., \& Horsham, M.A. (2007). Active packaging for fruits and vegetables. In: Intelligent and Active Packaging for Fruits and Vegetables, C. L. Wilson (Eds.), CRC Press, Boca Raton, 57-71.

Shetty, K.K., \& Dwelle, R.B. (1990). Disease and sprout control in individually film wrapped potatoes. American potato journal, 67(10), 705-718.

Shirazi, A., \& Cameron, A.C. (1992). Controlling relative humidity in modified atmosphere packages of tomato fruit. HortScience, 27(4), 336-339.

Suppakul, P., Miltz, J., Sonneveld, K., \& Bigger, S.W. (2003). Active packaging technologies with an emphasis on antimicrobial packaging and its applications. Journal of Food Science, 68(2), 408-420.

Tomar, O., \& Akarca, G. (2019). Farklı bitki ekstraktlarıyla kaplamanın kaşar peynirlerinin mikrobiyolojik ve duyusal kaliteleri üzerine etkileri. Avrupa Bilim ve Teknoloji Dergisi, $15,86-95$.

Tzeng, J.H., Weng, C.H., Huang, J.W., Shiesh, C.C., Lin, Y.H., \& Lin, Y.T. (2019). Application of palladium-modified zeolite for prolonging post-harvest shelf life of banana. Journal of the Science of Food Agriculture, 99(7), 3467-3474.

Veasna, H., Hwang, Y.-S., Choi, J.-M., Ahn, Y.-J., Lim, B.-S., \& Chun, J.-P. (2012). 1-Methylcyclopropene and carbon dioxide absorber reduce chilling injury of eggplant (Solanum melongena l.) during map storage. Protected Horticulture and Plant Factory, 21(1), 50-56.

Vermeiren, L., Devlieghere, F., van Beest, M., de Kruijf, N., \& Debevere, J. (1999). Developments in the active packaging of foods. Trends in Food Science \& Technology, 10(3), 77-86.

Vilela, C., Kurek, M., Hayouka, Z., Röcker, B., Yildirim, S., Antunes, M.D.C., Nilsen-Nygaard, J., Pettersen, M.K., \& Freire, C.S.R. (2018). A concise guide to active agents for active food packaging. Trends in Food Science \& Technology, $80,212-222$.

Watkins, C.B. (2000). Responses of horticultural commodities to high carbon dioxide as related to modified atmosphere packaging. HortTechnology, 10(3), 501-506.

Yildirim, S., Röcker, B., Pettersen, M.K., Nilsen-Nygaard, J., Ayhan, Z., Rutkaite, R., Radusin, T., Suminska, P., Marcos, B., \& Coma, V. (2018). Active packaging applications for food. Comprehensive Reviews in Food Science and Food Safety, 17(1), 165-199.

Zagory, D. (1995). Ethylene-removing packaging. In: Active food packaging, M. L. Rooney (Eds.), Springer, UK, 38-54. 